International Journal of Child, Youth and Family Studies (2015) 6(1): 52-67

\title{
FAMILY MATTERS: A STRENGTHS-BASED FAMILY RESILIENCY PERSPECTIVE TOWARD IMPROVING THE HEALTH OF YOUNG WOMEN EXPERIENCING HOMELESSNESS
}

\author{
Vanessa Oliver and Robyn LeBlanc
}

\begin{abstract}
The fostering of resilience in young people is based on a variety of social, cultural, and political factors that impact their interactions with and in the community. Through analysis of life history narratives of young women experiencing homelessness, this research links resilience not to traits inherent in individual young people, but to sustained social support. We emphasize the importance of key familial relationships as they relate to the development of resilience in young people. This research shows that positive connections within family, broadly defined to include families of choice and extended family networks, are vital to supporting young people experiencing homelessness. We also pay particular attention to the implications of family and resilience in the lives of Aboriginal young women experiencing homelessness, recognizing the significance of decolonization, cultural identity, and Indigenous world views in the success and stability of Aboriginal young people. This article argues that policy approaches to youth homelessness should address and eradicate policies that have a history of perpetuating culture erasure and the continuation of colonization. In order to enhance resilience, youth require a multi-systemic approach that provides support in the form of family reconnection, which acknowledges and respects a broader definition of family, moving beyond the nuclear family to extended family members, families of choice, and supportive communities.
\end{abstract}

Keywords: youth, homelessness, family, Aboriginal people, resilience, Canada

Vanessa Oliver, Ph.D. is an Assistant Professor of Youth and Children's Studies, Wilfrid Laurier University. 73 George Street, Brantford, Ontario, Canada, N3T 2Y3. Telephone (647) 281-6263. E-mail: voliver@wlu.ca

Robyn LeBlanc is a graduate student in the Department of Sociology, York University, 2060 Vari Hall, 4700 Keele Street, Toronto, Ontario, Canada, M3J 1P3. E-mail: leblancr@yorku.ca 
Resiliency theory originally emerged from the fields of behavioral psychology and epidemiology, where it focused mainly on the individual and on children in particular. Early theoretical work defined the resilient child as "the rare child who endures hardship and emerges as a competent and effectively functioning individual"; children who epitomized this definition were often referred to as "invulnerable", "stress-resilient”, "invincible”, or as "super kids" (Neiman, 1988, p. 18). These early conceptions, and specifically these labels, demonstrate a particular lack of attention to social structures and institutions, overemphasizing individual responsibility and obscuring the fact that none of us are invulnerable or invincible. That said, however, attention to the positive outcomes experienced by young people in difficult situations was a constructive step away from biomedical research that concentrated its focus on pathology and negative behaviors (Kidd, 2007; VanBreda, 2001).

That is why in this paper we subscribe to Ungar's (2007) definition of resilience: "[R]esilience is the outcome from negotiations between individuals and their environments, to maintain a self-definition as healthy” (p. 87). Ungar's ecological view of resilience recognizes the import of a variety of social, cultural, and political factors that impact the ability of a young person to be resilient. In other words, resilience is fostered in the individual through her or his interactions with and in the community, including the ability of that community to provide the necessary resources and supports (Libório \& Ungar, 2010). Because our work focuses on young women experiencing homelessness, this ecological context becomes even more salient when thinking about how to nurture resilience and resistance in young people living in exceptional circumstances. In the case of Aboriginal girls, the concept of resistance is integrally related to resilience insofar as Aboriginal peoples have resisted the impacts of colonialism and Eurocentric ways of knowing to secure, maintain, and grow their communities, and to retain Indigenous knowledge. This way of thinking about resiliency recognizes that homeless youth do not exist in a bubble - that context matters. Where one is and has been, what resources one has access to, and a variety of socio-historical factors (such as colonization) are much more telling than individual personal traits that are said to be innate rather than structural. We have seen through the course of this research that all of these young women possess forms of resilience, and that those who are the most resilient are also the ones who have the most social support. Resiliency is not rare; it is nurtured and created in supportive communities comprising a number of social actors.

Placing the emphasis on strength and capacity-building allows researchers and practitioners to move beyond "at risk" discourses of homelessness, which have been largely responsible for stigmatizing particular youth, families, and communities; individualizing collective responsibilities; and perpetuating racism and stereotypes. This is particularly true for Aboriginal women and girls, as Tuhiwai Smith (2002) argues: "Colonization is recognized as having had a destructive effect on Indigenous gender relations which reached out across all spheres of Indigenous society” (p. 24). Smith (2003) also emphasizes that the economic and political success of the colonial enterprise relied on the subjugation of Indigenous women. Legislation, discourse, and popular culture representations such as Pocahontas, marginalized Indigenous women through hyper-sexualization, exoticism, and violence rooted in structural mechanisms. These forms of violence have been "perpetrated on Aboriginal bodies throughout Canada's history, a colonial violence that has not only enabled white settlers to secure the land but to come to know themselves as entitled to it” (Razack, 2002, p. 129, emphasis in original). The present-day effects of these ideas and policies are evidenced in the growing number of 
International Journal of Child, Youth and Family Studies (2015) 6(1): 52-67

missing and murdered Aboriginal women, and the lack of official response from the justice system (Native Women's Association of Canada, 2010; Native Youth Sexual Health Network \& Families of Sisters in Spirit, 2013). Thus, particularly for Aboriginal young people, discourses of risk tend to obscure the fact that young people are placed at risk by social and political structures - marginalization does not happen by accident (Danforth, 2013). From an ecological perspective, then, nurturing resilience means collaboration in and with communities that are culturally-based, faith-based, service-based, and support-based - including institutions of health care, social service, and education provision.

This type of strategy should not be viewed as a "pick yourself up and dust yourself off" or "pull up your socks" approach to resilience, which creates further vulnerability by stressing personal responsibility for circumstances that are, in fact, outside of the individual's control (Schwartz, 1997). Instead of thinking simply about individual young people who are experiencing homelessness, we need to be thinking about more dynamic and complex processes that assist or impede young people's abilities to resist and persevere in the face of adversity. Individualizing approaches fail to recognize that resilience is not a quality inherent in some young people but not in others. In making an assumption that all young people's stories include elements of resistance, and in maintaining the belief that narrative, as a social construct, can be reconstructed and improved upon, young people and their supporters can create narratives of strength and resistance rather than narratives of risk. Indeed, multiple studies have found that significant relationships with other people have the greatest impact on resilience (Walsh, 2012; Jordan, 2013; Williams \& Merten, 2014). These relationships take many forms - kinships, intimate partnerships, mentors, service providers, and social workers, to name but a few - but the key components of these relationships are a belief in a young person's potential, and holistic support and encouragement of their goals (Walsh, 2012). This paper will focus in particular on the role of key familial relationships as they pertain to the creation and maintenance of resilience among the young women who participated in this research. Because half of the participants in this work self-identified as Aboriginal people, we will pay particular attention to the implications of family and resilience for Aboriginal young women.

\section{Method}

This research uses a qualitative, multiple-case study approach to analyze the life history narratives of eight young women experiencing homelessness, in order to investigate the factors that they perceive to have impeded or facilitated their ability to access health and social services, and how these factors have influenced their overall health and well-being. For the purpose of this research, health-seeking behavior is the search for access to health services and healthy situations that enable young women to treat illness and preserve wellness (Oliver, 2013). Their life narratives explain how these young women define their own health, what health issues they are experiencing, what services they use in seeking to care for themselves, and the factors they perceive to have influenced their access to health services. This research was conducted in Toronto, Ontario, Canada.

Life history interviews were completed with eight young women recruited from shelters, and from street visits to those who were not sheltered. Life history methodologists believe that gaining insight into the lives of particular individuals allows for the understanding of broader communities and, by extension, for the partial explanation of broader social conditions (Cole \& 
International Journal of Child, Youth and Family Studies (2015) 6(1): 52-67

Knowles, 2001). In so doing, relations of power and dominant discourses that may have been otherwise obscured become clearer (Oliver, 2013). Life history employs particular methods to achieve its ends, the most important of which are in-depth semi-structured interviews, followed by thematic interpretation, analysis, and theorization (Cole \& Knowles, 2001). Life history research is not just simple information transfer, but rather narrative work that requires attention to detail, context, and collaborative constitution between storyteller and listener (Gubrium \& Holstein, 2009). The interviews generally took four to six hours, spread out over several sittings, the amount of time necessary to complete full life-history interviews (Leavy, 2007). An interview protocol outlined questions that traced the young women's life histories in chronological order; however, participants often talked about their lives in non-sequential order as one experience triggered another that may have occurred earlier or later in the life course.

This research also used participant observation when young women allowed us to shadow them through their days (Patton, 2002). These observations provided data that demonstrated the amount of work that the young women put into meeting their daily needs, as well as the daily realities of life in the shelter or on the street. The young women interviewed here represent racial and sexual diversity, and range in age from 15 to 21 years, mirroring the heterogeneity of the population. Four of the young women who participated self-identified as Aboriginal, two selfidentified as non-Aboriginal women of colour, and three self-identified as lesbian or bisexual. Most of the young women struggled with mental health issues and all but one were survivors of physical or sexual violence. All of the young women demonstrated exceptional resilience in the face of homelessness. At the end of the final interview, each participant was asked to complete a demographics form. The demographics of the eight young women are presented in Table 1.

Upon completion of the interviews, all transcripts were transferred into qualitative data management software, NVivo. Coding and analysis of data commenced using the constant comparative method outlined by Strauss and Corbin (1990). A preliminary coding framework of relevant themes garnered from the literature was developed prior to conducting the interviews. After the interviews took place, the coding framework was revised to incorporate themes generated through an adaptation of the constant comparative method (Taylor \& Bogdan, 1998). This type of coding involves the development of codes that describe respondents' stories in their own words. As codes were developed, they were applied and compared to newly collected data and modified as necessary. Descriptive codes were then combined to develop theoretical or analytical themes. 
International Journal of Child, Youth and Family Studies (2015) 6(1): 52-67

Table 1

Demographics of the participants

\begin{tabular}{|lclll|}
\hline Participant & Age & Ethnicity & Sexual Orientation & Education \\
\hline Danika & 21 & West Indian & Heterosexual & Some University \\
Radha & 19 & South Asian & Mostly heterosexual & Grade 12 \\
Jean & 20 & Ojibwe & Lesbian & Grade 12 \\
Savannah & 19 & Native Canadian & Heterosexual & Grade 12 \\
Arielle & 20 & Congolese & Heterosexual & Some high school \\
Faith & 17 & Métis & Mostly lesbian & Grade 10 \\
Raven & 16 & Caucasian/Native & Mostly lesbian & Grade 9 \\
Erin & 15 & Caucasian & Heterosexual & Grade 8 \\
\hline
\end{tabular}

Note: All names in the first column are pseudonyms chosen by the participants for their own protection.

\section{Families}

Resiliency research has demonstrated that strong connections and caring relationships between children and adults both inside and outside the home cultivate resilience in adolescence (Werner \& Smith, 1992). In an examination of personal support systems, the family has also been shown to be an important factor in preventing young people from engaging in practices that can be harmful to their health and development. As this research will show, connections to extended family members in cases where immediate family members are abusive or absent are understood as vital to many young women experiencing homelessness (Rew \& Horner, 2003).

Walsh (2012) advocates a family resilience approach which builds what she calls "relational lifelines" to improve resilience through exchanges and relationships with the kinship network. Extended family and familial social networks can be of critical importance in supporting homeless young people, providing financial and/or emotional support. Creating resilience in this way becomes an interactive process that works differently for different youth. Some young people have weak or no attachment to their parent or parents of origin, but maintain strong attachments to family other than their birth parents, while others have complex, but workable relationships with their birth parents. The most introspective of the participants, Danika, had an enormous degree of empathy for the other women living in the shelter, even those who bullied her. Although she was often demure and shy, her determination to change her circumstances was fierce. Danika, a university student who was living independently in the shelter after her parents lost their jobs and became unable to afford adequate nutrition and housing for the family, discussed her nightly phone calls with her mother and the complex, but crucial, relationship they have:

I talk to my mom every night.... You know they were good, they loved me, we were close... God, I love them, but they just disappointed me so many times. It's so hard. It's so hard to deal with it. 
International Journal of Child, Youth and Family Studies (2015) 6(1): 52-67

Having left her family home due to her parents' struggles with poverty and unemployment, Danika realized that her family connection was sustaining her, even though her parents could not financially support her. The structural inequities facing her parents and creating poverty need critical recognition, and should be recognized as centrally responsible for Danika's situation. Nonetheless, Danika was one of the most resilient women we talked with, managing to balance her university degree requirements, a part-time job, and an often chaotic life in the shelter.

Radha was an award-winning writer who planned to write her own life story into a novel after graduating from university. She was in her last year of high school and living in the shelter after her parents divorced and her mother became depressed. Despite her separation from her parents, she admitted:

I think it's easier because I know to some degree my parents are still there. I've always wondered if I could find the strength or the willpower to just completely shut them out of my life. I don't know if I could.

Again, although the relationship was complex and strained, Radha was still aware of the ways in which even a partial relationship with her parents created a scaffolding of support.

While the process will inevitably be context-specific, it is worth noting that family relationships remain hugely important to the success and stability of the young women in this research. Given the nature of homelessness, many people assume that homeless young people do not have ties, or do not care to have ties, with their families; however, this is rarely the case (Oliver, 2013; Winland, Gaetz, \& Patton, 2011). Although many of the young women in this research come from abusive homes, their extended families or kinship networks are not a part of - and are often a refuge from - the abusive situations. Although commonly employed in the policy arena, narrow definitions of family that support a traditional and conservative view of family as consisting of those inside a nuclear family unit are hugely limiting, and fail to account for the wide range of personal connections that exist outside of that definition, be they extended biological families or families of choice (Quinless, 2013; Ajandi, 2011). Grandmothers, in particular, were often discussed as beloved and supportive, providing safe spaces for their grandchildren in times of need (McCaffrey, 2010; Sands, Goldberg-Glen, \& Shin, 2009).

Savannah was self-possessed and had a knack for storytelling, which she attributed to growing up in a storytelling culture. She was an young Aboriginal woman who was living in the shelter after years of struggling with abusive partners and chronic substance use. She spoke confidently and laughed easily. Savannah often discussed her grandma as her primary source of support, and her grandmother's home as the place she most considered her own:

Anyways, my grandma, around wintertime, my grandma took me to live with her for about a couple weeks, just to get away from London. And then, I was doing good, I was staying away from doing all that stuff. ... Yeah. With my grandma ... that's my home.

When her substance use or intimate relationship issues became too overwhelming, Savannah relied on her grandmother's support to regroup, reconnect, and restabilize. 
International Journal of Child, Youth and Family Studies (2015) 6(1): 52-67

Raven was an avid anime fan whose enthusiasm and laughter were contagious. She grew up in rural Ontario where she struggled with homophobia and transphobia at school and at home. Raven also relied on her grandmother as a source of non-judgmental and supportive care when her mother rejected her lesbianism:

"Nana, can we come live with you...." And she's like, "Yeah, that's fine that's fine. It's okay, I love you and I love your girlfriend," and stuff like that. So, that was cool.... She didn't care how we were, she didn't care that we were lesbians together. She didn't care. She was actually quite happy.

Clearly, nurturing these relationships and providing support for sustaining these familial connections is one critical piece of supporting young women in healing and in transitioning out of homelessness.

A recent evaluation of an innovative program at Toronto's Eva's Initiatives that works to reconnect youth experiencing, or at risk of experiencing, homelessness with their families and communities, demonstrates that although strengthening connection to family is often part of the solution, this approach to youth homelessness is largely ignored in Canadian policy responses (Winland et al., 2011; Elze, 2012). Instead, policy responses have largely assumed that family is not or should not be involved, that the family is part of a young person's past, but not part of her or his future (Winland et al., 2011; Fitzgerald, 1995; Barker, 2014; la Haye et al., 2012). While family reconnection is not appropriate or advisable in every case, families are often key members in the support systems of young people, as the Eva's Initiatives Family Reconnect project shows, and self-sufficiency might be better achieved through these reconnections.

Faith, a young woman who grew up in rural Ontario, experienced homophobia and sexual violence from an early age. She was well organized and responsible, which made it possible for her to live independently on very little income with her partner, Raven. As Faith's relationship with her aunt illustrated, extended family members have an important role to play in encouraging healthy decision-making:

I'd promised my aunt, which is the only person in my family I've ever looked up to, she's only 24, so she's not that much older than me. I promised her that I would live straight and not ever do shit like that, and I kept my word to her.

In other words, youth can still be independent while being supported in their transition by the family members with whom they have positive attachments. The evaluation of the Family Reconnect program demonstrates that this approach is working and suggests that governments and policy-makers should provide more support for this type of programming.

\section{Family and the Aboriginal Context}

Cultural identity has been singled out as a critical factor in the study of resiliency in youth (H. I. McCubbin, A. I. Thompson, E. A. Thompson, Elver, \& M. A. McCubbin, 1998). Individuals who are members of racialized groups that have been stigmatized or oppressed have a particular stake in the construction of resiliency theory. Maintaining a healthy cultural identity requires that cultural strengths and histories be acknowledged and positively recognized (McCubbin et al., 1998). HeavyRunner and Morris (1997) argue that when cultural values are nurtured in children, children are better able to develop self-confidence and are better equipped 
International Journal of Child, Youth and Family Studies (2015) 6(1): 52-67

to face challenges. In a colonial society that can be particularly racist and hostile to Aboriginal young people, having a strong and positive cultural identity can assist in maintaining self-esteem and a sense of belonging.

More recent work in resilience studies is speaking to the ways in which resilience is constructed differently in different contexts and locations. For example, as a result of colonization in countries around the world, resistance to cultural hegemony and cultural erasure are important points in maintaining and sustaining resilience for people who have been marginalized and oppressed by systemic racism and discrimination (Libório \& Ungar, 2010; Walia, 2013). As Simpson (2004) argues, decolonization requires "recovering and maintaining Indigenous worldviews, philosophies, and ways of knowing, and applying those teachings in a contemporary context represents a web of liberation strategies Indigenous Peoples can employ to disentangle themselves from the oppressive control of colonizing state governments” (p. 1). Part of this decolonization effort also means that concerted attention needs to be paid to differences in family functioning in conversations about resilience, creating a "culturally negotiated interpretation" of what resilience means and how it is created (Simpson, 2004, p. 328). This culturally and historically mediated negotiation and understanding of resilience certainly applies to Aboriginal people on Turtle Island (North America). Many Indigenous models of parenting and family believe that each person has a relationship and a responsibility to the children in the community around them, whether those children are biologically related to them or not (Baskin, 2013; Blackstock \& Trocme, 2005). Family, then, takes on a broader, more inclusive definition that encompasses extended family, such as grandparents and aunts, and also the larger community in which a child is raised. Given these holistic Indigenous world views, there is no stigma attached to living with people who are not one's birth parents or parents of origin (Blackstock \& Trocme, 2005). As Baskin (2011) points out, living with extended family or in different households at different times has been seen as the norm rather than the exception.

Indigenous world views are highly salient in the discussion of resiliency when allying with Aboriginal youth who are experiencing homelessness. Recent reports suggest that Aboriginal people comprise $15 \%$ of the homeless population in Toronto, and that many of these people are youth (Golden, Currie, Greaves, \& Latimer, 1999; Baskin, 2013). This number constitutes a vast overrepresentation given that Statistics Canada (2008) shows that only 4\% of the national population identify as Aboriginal. The number of Aboriginal people experiencing homelessness may well be higher than the $15 \%$ reported, as accurate counts are difficult to obtain with the transient and hidden nature of homeless populations, and given that numbers are largely counted from the shelter system, which only accounts for a specific type of homelessness. For Aboriginal youth, home and its definition are complicated by the dislocation and relocation of Aboriginal people in colonial Canada. From the theft of Aboriginal lands, to forced relocation onto reservations, to residential schools, to the continued neo-colonial government policies in place today, the concept of home is one that must be considered within this cultural and historical context of attempted cultural genocide and forced assimilation.

The Indian Act, which was passed in Canada in 1876, inscribed a number of sexist rules and regulations into legislation. Although the Act has been oppressive to all Aboriginal people, experts have outlined the ways in which it is and has been particularly damaging for Aboriginal women (Bourassa, McKay-McNabb, \& Hampton, 2004; Anderson, 2010; Sikka, 2009). Prior to 1985, under the Indian Act, Indian women who married non-Indian men were stripped of their 
International Journal of Child, Youth and Family Studies (2015) 6(1): 52-67

status and band membership, also depriving their children of "official” cultural recognition (Bourassa et. al., 2004; Anderson, 2010). Colonial policies eliminated matrilineal inheritance, so that women were unable to own or inherit property, and again, these repercussions were passed down to their children (Anderson, 2010; Downe, 2006). Further community breakdown and forced family dissolution were also direct results of the residential school system, which removed Aboriginal children from their families, their communities, their languages, and their cultures. Likewise, during the so-called "60s Scoop" in the 1960s, child welfare agents removed Aboriginal children from their families placing them with non-Aboriginal families, in most cases completely severing ties between the child and his or her home community (Blackstock \& Trocme, 2005). Department of Indian Affairs statistics indicate that over 11,000 status Indian children were placed for adoption between 1960 and 1990 (Blackstock \& Trocme, 2005). Today, there are more Aboriginal children living in state care than there were at the height of the residential school years, creating what is called the "Millennium Scoop” (Beaucage, 2011).

For Aboriginal girls, the outcomes of this colonial, cultural, and familial erasure are manifold. Intergenerational relationships between grandparents, parents, and children were, and continue to be, severed; traditional kinship models based on community or extended family care have been largely ignored or dismissed by Euro-Western child welfare workers and legislation; and children have been moved around and placed into state care (Anderson, 2010; Downe, 2006). As a result, Aboriginal girls are more likely to be incarcerated, are more often sexually exploited, and are more likely to experience racism, discrimination, and violence than are nonAboriginal girls (Blackstock \& Trocme, 2005; Downe, 2006; Sikka, 2009; Walia, 2013).

The young women participating in this research traced their own experiences and relationships to colonial structural violence. When Savannah talked about her grandmother, who was her greatest source of strength and connection, she saw how the history of residential schools impacted her family:

All [my grandma] likes to do is like stay at home, watch her soap operas and go to her senior classes and go to bingo. And I'm happy for her to actually go and do something, because there was times she went through depression and like she would just like ... it was to the point where she would just think of something and cry.

Resilience situated in this context of attempted cultural erasure takes on important meanings, while hundreds of years of resistance and community strength paints a more complex picture still. Considering what creates, maintains, and sustains resilience in Aboriginal young people requires a decolonization lens that simultaneously keeps an eye on years of oppression, while staying focused on the strengths, resistance, and self-determination inherent in Aboriginal identities. Reclaiming, owning, and practicing cultural traditions are key pieces of nurturing resilience in Aboriginal young women experiencing homelessness. As Savannah said, "I want to stay close to my Native people. They give me something that other people can't. They just understand me better and make me feel stronger."

The role of government services in contributing to the physical and psychic homelessness experienced by too many Aboriginal young women is central to the discussion of colonization and neo-colonialism, Aboriginal youth, family resilience, and homelessness. Talking about the role of family in young people's resilience means critically analyzing the structural, social, and political factors that work to disrupt Aboriginal families in the first place. As children have been 
International Journal of Child, Youth and Family Studies (2015) 6(1): 52-67

removed from their communities, little attention has been paid to the structural risk factors that make it difficult for families to cope: intergenerational trauma, poverty, unemployment, inadequate housing conditions, and poor sanitation infrastructure.

The policy that currently bolsters child protection work, Directive 20-1 (Aboriginal Affairs and Northern Development Canada, 2012), operates from a perspective that advocates the best interests of children, but does so from a narrowly-defined, Eurocentric understanding of families and, especially, the nuclear family unit. The Directive has been criticized for emphasizing child removal and placement instead of providing resources that would support communities to care for children at home (Blackstock \& Trocme, 2005; MacDonald \& Ladd, 2000). Indigenous world views also seek to nurture the child, but do so through the assistance of the larger community, all of whose members can serve as a child's family (Rutman, Field, Jackson, Lundquist, \& Callahan, 2005). Extending from the residential school mentality, child protection has become an arm of the colonial machine. From the 60s Scoop that took children from their home communities and placed thousands of Aboriginal children in the care of nonAboriginal families, to present day policies that fail to recognize the self-determination and advocacy of Aboriginal communities, child protection has removed children from their homes rather than providing adequate, sustainable, and self-determined social and financial supports that would allow communities to care for their children (Baskin, 2013).

Jean was an amazing singer with a powerful imagination and a history of constant upheaval in the child welfare system. Jean's experience illustrates the impact of this disconnection from her home community:

I liked living on the res. Not in the home how it was when my mom had me, but how it was when my grandma had me. When I left there I went to places with non-Aboriginal people. It was a lot different. They didn't really understand me and I acted out. And then I couldn't be in foster care anymore so I had to go to a group home that was even worse.

All of the Aboriginal young women who were part of this research had been involved in the child welfare system at some point in their life history. Unfortunately this experience resonates with a great deal of research that shows that many Aboriginal youth (estimated at between 25\% and 50\%) who experience homelessness enter the shelter system following negative experiences with foster care or group homes (Maclean, Embry, \& Cauce, 1999; Lindsey, Kurtz, Jarvis, Williams, \& Nackerud, 2000; Public Health Agency of Canada, 2006; Baskin, 2013).

As Baskin (2013) argues, in foster homes, which through the lens of colonialism are thought to be better for children than their homes in the community, Aboriginal young people are removed from their cultures, their languages, and their traditions, as well as from their families, essentially divorcing them from critical pieces of their identity. Child welfare has undermined Indigenous ways of knowing at the expense of Aboriginal children and their families (Blackstock \& Trocme, 2005). When various levels of government effectively outlaw Indigenous forms of parenting, investing non-Aboriginal people with the right to remove children, we see the continuation of colonization. Families and young people are denied opportunities to foster resilience in the face of cultural erasure and misidentification. As we have shown, families are critical players in supporting young people in their transitions out of homelessness and into independent living. When children are removed from their families, not to mention told through racist, Eurocentric policies and discourses that those families and communities are somehow 
International Journal of Child, Youth and Family Studies (2015) 6(1): 52-67

lacking, it should come as no surprise that Aboriginal youth are overrepresented in the homeless population. Creating, maintaining, and sustaining resilience in Aboriginal young people means supporting them to connect with their families and cultures; it means decolonizing the system that perpetuates the injustice of removing Aboriginal children from their communities; it means ensuring that Aboriginal young people are proud and aware of the strengths, resistance, and determination of their people.

Developing First Nations child and family services agencies has been a step in this direction, and Blackstock and Trocme (2005) argue that these agencies have

been very successful at ensuring children are cared for in the community whenever possible, and when placement outside of the community is required steps are taken to ensure the child has access to cultural and linguistic services and to family whenever possible. (p. 17)

Bill 210 amended the Ontario Child and Family Services Act in 2006 to move off-reserve child protection in this direction, focusing on family-centered care that involves extended family and community solutions rather than those that place children in the care of complete strangers (Legislative Assembly of Ontario, 2006). The amendment also underscores alternative conflict resolution strategies and planning for permanent care to occur through the extended family or through adoptions within the community, rather than outside of it (Beaucage, 2011; Baskin, 2013). Strengthening families, which serves the end goal of creating resilience, requires processes of decolonization that first recognize the impacts of colonization and undo the systemic discrimination that is built into the very fabric of the social policy landscape. This requires that the definition of family be extended to include forms of family that may fall outside of Eurocentric expectations; however, the effort must extend beyond simple redefinition to integrate and privilege Aboriginal world views, Aboriginal decision-makers, and Aboriginal communities (Blackstock \& Trocme, 2005). Despite years of assimilationist policies, Aboriginal people have fought for and maintained their right to self-determination. Aboriginal young people have a right to this history of resistance and strength on which they can build their identities, their self-esteem, and their resilience (Anderson, 2010; Downe, 2006).

\section{Conclusion}

Decades ago, Coleman (1988) argued that the most important thing we can do for children is to link them into the social fabric. Applying a strengths-based approach to youth homelessness, combined with a decolonization and social justice mandate to youth's issues of housing, financial support, food insecurity, health, and employment, would allow for genuine support rather than simple assistance. The implementation of this approach, however, would be problematic and difficult in a system that is increasingly problem-oriented and tending to identify youth by their criminal behavior, mental illnesses, and estrangement from the formal education system (Lindsey et al., 2000). A more positive approach would enable youth and the people who work with them to focus attention on the familial and community assets that would help fortify youth and support them in being better able to deal with their challenges. Resiliency research provides a framework for social change that, beginning in youth, could be a source of support throughout the life course. 
Families (broadly defined), communities, and well-allocated, sustainable social resources are all factors that create and sustain resilience. Familial ties are crucial to the positive trajectories of youth experiencing homelessness; however, these ties require support, flexibility, and an awareness that family reconnection cannot be successful without sustainable support and programming that caters to these needs, framing them within their historical and social contexts. Thus, multi-systemic approaches are necessary to facilitate resilience and foster familial relationships (Walsh, 2012). Such approaches would require coordination between ministries, between service providers, and between and within communities; moreover, they would require genuine engagement with, and respect for, Indigenous world views.

Without genuinely listening to, and actually hearing, these young women's stories, we are neglecting their strengths and their everyday assets. Hearing stories provides researchers and clinicians a window to locate what Ungar (2007) has called "narratives of resilience": positive self-constructions that are concealed beneath survival behaviors and chaotic environments (p. 90). Young women are more than capable of defining their own strengths and weaknesses, and of attributing those to social locations, personal strengths, cultural traditions, and life histories. One way that resilience is negotiated and strengthened is through a young person's ability to access culturally safe resources, coupled with the larger community's ability to provide the necessary resources in socially just ways (Libório \& Ungar, 2010). Resilience does not inhere in some young people and not in others. Resilience is grown, strengthened, and nurtured in supportive communities that are attentive to and support the needs of extended families and families of choice. Through these relationships young people experiencing homelessness resist, reconnect, and re-envision the possibilities for achieving their goals and ambitions. 
International Journal of Child, Youth and Family Studies (2015) 6(1): 52-67

\section{References}

Aboriginal Affairs and Northern Development Canada. (2012). National social programs manual. Retrieved from https://www.aadncaandc.gc.ca/eng/1335464419148/1335464467186\#chp6-3

Ajandi, J. (2011). Single mothers by choice: Disrupting dominant discourses of the family through social justice alternatives. International Journal of Child, Youth and Family Studies, 2(3/4), 410-431.

Anderson, K. (2010). Native women, the body, land, and narratives of contact and arrival. In H. Lessard, R. Johnson, \& J. Webber (Eds.), Storied communities: The role of narratives of contact and arrival in constituting political community (pp. 167-188). Vancouver: UBC Press.

Barker, J. (2014). Alone together: The strategies of autonomy and relatedness in the lives of homeless youth. Journal of Youth Studies, 17(6), 763-777. $\mathrm{http}: / / \mathrm{dx}$. doi.org/10.1080/13676261.2013.853874

Baskin, C. (2011). Strong helpers' teachings: The value of Indigenous knowledges in the helping professions. Toronto: Canadian Scholars' Press.

Baskin, C. (2013). Shaking off the colonial inheritance: Homeless Indigenous youth resist, reclaim and reconnect. In S. Gaetz, B. O’Grady, K. Buccieri, J. Karabanow, \& A. Marsolais (Eds.), Youth homelessness in Canada: Implications for policy and practice (pp. 405-424). Toronto: The Canadian Homelessness Research Network Press.

Beaucage, J. (2011). Children first: The Aboriginal advisor's report on the status of Aboriginal child welfare in Ontario. Toronto: Ontario Ministry of Child and Youth Services, Government of Ontario.

Blackstock, C., \& Trocmé, N. (2005). Community-based child welfare for Aboriginal children: Supporting resilience through structural change. Social Policy Journal of New Zealand, 24, 12-33.

Bourassa, C., McKay-McNabb, K., \& Hampton, M. (2004). Racism, sexism and colonialism: The impact on the health of Aboriginal women in Canada. Canadian Woman Studies, 24(1), 23-29.

Cole, A. L., \& Knowles, G. J. (2001). Lives in context: The art of life history research. Walnut Creek, CA: AltaMira Press.

Coleman, J. S. (1988). Social capital in the creation of human capital. The American Journal of Sociology, 94(Supplement), S95-S120.

Danforth, J. (2013). Marginalization doesn't happen by accident. Keynote address, International Women's Week, March 6, Mount Allison University, Sackville, New Brunswick, Canada. 
International Journal of Child, Youth and Family Studies (2015) 6(1): 52-67

Downe, P. J. (2006). Aboriginal girls in Canada: Living histories of dislocation, exploitation and strength. In Y. Jiwani, C. Mitchell, \& C. Steenbergen (Eds.), Girlhood: Redefining the limits (pp. 1-15). Montreal: Black Rose Books.

Elze, D. E. (2012). In-home services for families of LGBTQ youth. National Resource Center for In-Home Services. Retrieved from http://c.ymcdn.com/sites/www.mccca.org/resource/resmgr/Files/LGBTissuebriefwithprac tice.pdf

Fitzgerald, M. D. (1995). Homeless youth and the child welfare system: Implications for policy and service. Child Welfare, 74(3), 717-731.

Golden, A., Currie, W. H., Greaves, E., \& Latimer, E. J. (1999). Taking responsibility for homelessness: An action plan for Toronto. Toronto: City of Toronto.

Gubrium. J. F.. \& Holstein. J. A. (2009). Analyzing narrative reality. Thousand Oaks, CA: Sage. http://dx.doi.org/10.4135/9781452234854

HeavyRunner, I., \& Morris, J. S. (1997, Spring). Traditional Native culture and resilience. Research Practice, 5(1). Minneapolis, MN: Center for Applied Research and Educational Improvement, University of Minnesota.

Jordan, J. V. (2013). Relational resilience in girls. In S. Goldstein \& B. Brooks (Eds.), Handbook of resilience in children (pp. 73-86). New York: Springer US. http://dx.doi.org/10.1007/978-1-4614-3661-4_5

Kidd, S. A. (2007). Youth homelessness and social stigma. Journal of Youth and Adolescence, 36(3), 291-299. http://dx.doi.org/10.1007/s10964-006-9100-3

la Haye, K., Green, H. D., Kennedy, D. P., Zhou, A., Golinelli, D., Wenzel, S. L., \& Tucker, J. S. (2012). Who is supporting homeless youth? Predictors of support in personal networks. Journal of Research on Adolescence, 22(4), 604-616. http://dx.doi.org/10.1111/j.1532-7795.2012.00806.x

Leavy, P. L. (2007). The practice of feminist oral history and focus group interviews. In S. Hesse-Biber \& P. Leavy (Eds.), Feminist research practice (pp. 149-186). London: Sage. http://dx.doi.org/10.4135/9781412984270.n6

Legislative Assembly of Ontario. (2006). Bill 210, Child and Family Services Law Amendment Act, 2006. Toronto: Author. Retrieved from http://www.ontla.on.ca/web/bills/bills_detail.do?locale=en\&BillID=193\&detailPage=bill s_detail_about

Libório, R. M. C., \& Ungar, M. (2010). Children’s perspectives on their economic activity as a pathway to resilience. Children \& Society, 24(4), 326-338. doi:10.1111/j.10990860.2009.00284.x

Lindsey, E. W., Kurtz, D., Jarvis, S., Williams, N. R., \& Nackerud, L. (2000). How runaways and homeless youth navigate troubled waters: Personal strengths and resources. Child and Adolescent Social Work Journal, 17(2), 115-140.

MacDonald, R., \& Ladd, P. (2000). First Nations child and family services joint national policy review. Ottawa: Assembly of First Nations. 
International Journal of Child, Youth and Family Studies (2015) 6(1): 52-67

Maclean, M. G., Embry, L. E., \& Cauce, A. M. (1999). Homeless adolescents’ paths to separation from family: Comparison of family characteristics, psychological adjustment, and victimization. Journal of Community Psycholoqy, 27(2), 179-187. http://dx.doi.org/10.1002/(sici)1520-6629(199903)27:2\%3C179::aid-jcop5\%3E3.0.co;2-s

McCaffrey, S. (2010). Kookum knew... exploring historical contexts: Aboriginal people, the justice system, and child welfare. International Journal of Child, Youth and Family Studies, 1(3/4), 340-347.

McCubbin, H. I., Thompson, A. I., Thompson, E. A., Elver, K. M., \& McCubbin, M. A. (1998). Ethnicity, schema, and coherence: Appraisal processes for families in crisis. In H. I. McCubbin, E. A. Thompson, A. I. Thompson, \& J. E. Fromer (Eds.), Stress, coping, and health in families: Sense of coherence and resiliency (pp. 41-70). Thousand Oaks, CA: Sage.

Native Women's Association of Canada. (2010). A culturally relevant gender application protocol. Ottawa, ON: Author.

Native Youth Sexual Health Network \& Families of Sisters in Spirit. (2013). Police (in)justice: Responding together to change the story. Collaborative statement and resources. Toronto: The Native Youth Sexual Health Network.

Neiman, L. (1988). A critical review of resiliency literature and its relevance to homeless children. Children's Environments Quarterly, 5(1): 17-25.

Oliver, V. (2013). Healing home: Health and homelessness in the life stories of young women. Toronto: University of Toronto Press.

Patton, M. Q. (2002). Qualitative evaluation and research methods. Thousand Oaks, CA: Sage Publications.

Public Health Agency of Canada. (2006). Street youth in Canada: Findings from enhanced surveillance of Canadian street youth, 1999-2003. Ottawa: Author. Retrieved from http://www.phac-aspc.gc.ca/std-mts/reports_06/pdf/street_youth_e.pdf

Quinless, J. M. (2013). First Nations teenaged female lone parent families in Canada: Recognizing family diversity and the importance of networks of care. The International Indigenous Policy Journal, 4(1), 12. http://dx.doi.org/10.18584/iipj.2013.4.1.12

Razack, S. (Ed.). (2002). Race, space, and the law: Unmapping a white settler society. Toronto: Between the Lines.

Rew, L., \& Horner, S. D. (2003). Personal strengths of homeless adolescents living in a high-risk environment. Advances in Nursing Science, 26(2), 90-101. http://dx.doi.org/10.1097/00012272-200304000-00002

Rutman, D., Field, B., Jackson, S., Lundquist, A., \& Callahan, M. (2005). Perspectives of substance using women and human service practitioners: Reflections from the margins. In D. L. Gustafson (Ed.), Unbecoming mothers: The social production of maternal absence (pp. 227-249). New York: Haworth Clinical Practice Press. http://dx.doi.org/10.4324/9781315044101 
International Journal of Child, Youth and Family Studies (2015) 6(1): 52-67

Sands, R. G., Goldberg-Glen, R. S., \& Shin, H. (2009). The voices of grandchildren of grandparent caregivers: A strengths-resilience perspective. Child Welfare, 88(2), 22-45.

Schwartz, R. (1997). Don't look back. Networker, (March/April), 40-47.

Sikka, A. (2009). Trafficking of Aboriginal women and girls in Canada. Ottawa: Institute on Governance. Retrieved from http://iog.ca/wp-content/uploads/2012/12/May2009_trafficking_of_aboriginal_women-1.pdf

Simpson, L. R. (2004). Anticolonial strategies for the recovery and maintenance of Indigenous knowledge. The American Indian Quarterly, 28(3), 373-384. http://dx.doi.org/10.1353/aiq.2004.0107

Smith, A. (2003). Not an Indian tradition: The sexual colonization of Native peoples. Hypatia, 18(2), 70-85. http://dx.doi.org/10.1353/hyp.2003.0042

Statistics Canada. (2008). Aboriginal peoples (Release no. 5: January 15, 2008). Retrieved from https://www12.statcan.gc.ca/census-recensement/2006/rt-td/ap-pa-eng.cfm

Strauss, A., \& Corbin, J. M. (1990). Basics of qualitative research: Grounded theory procedures and techniques. Thousand Oaks, CA: Sage Publications, Inc.

Taylor, S., \& Bogdan, R. (1998). Introduction to research methods. New York: Wiley.

Tuhiwai Smith, L. (2002). Decolonizing methodologies: Research and Indigenous peoples. New York: Zed Books Ltd.

Ungar, M. (2007). Grow 'em strong: Conceptual challenges in researching childhood resilience. In A. Best (Ed.), Representing youth: Methodological issues in critical youth studies (pp. 84-109). New York: New York University Press.

Van Breda, A. D. (2001). Resilience theory: A literature review. Pretoria, South Africa: South African Military Health Service.

Walia, H. (2013). Undoing border imperialism. Oakland, CA: AK Press.

Walsh, F. (2012). Facilitating family resilience: Relational resources for positive youth development in conditions of adversity. In M. Ungar (Ed.), The social ecology of resilience: A handbook of theory and practice (pp. 173-185). New York: Springer. http://dx.doi.org/10.1007/978-1-4614-0586-3 15

Werner, E. E., \& Smith, R. S. (1992). Overcoming the odds: High risk children from birth to adulthood. New York: Cornell University Press.

Williams, A. L., \& Merten, M. J. (2014). Linking community, parenting, and depressive symptom trajectories: Testing resilience models of adolescent agency based on race/ethnicity and gender. Journal of Youth and Adolescence, 43(9), 1563-1575. doi: 10.1007/s10964-014-0141-8

Winland, D., Gaetz, S., \& Patton, T. (2011). Family matters: Homeless youth \& Eva's initiative's family reconnect program. Toronto: The Canadian Homelessness Research Network Press. 